\title{
Structurally Informative Isotopic Shifts in Ion Mobility Spectra for Heavier Species
}

Pratima Pathak, Matthew A. Baird, Alexandre A. Shvartsburg*

Department of Chemistry, Wichita State University, 1845 Fairmount, Wichita, Kansas 67260, United States

* alexandre.shvartsburg@wichita.edu

\section{Supporting Information}

Table S1. Sources of used DBA and TBA standards

Figure S1. Geometries of DBA and TBA isomers studied in this work

Figures S2. Geometries of isotopomers enumerated in Table 2, ordered and color-coded as 2,$3 ; 2,4 ; 2,5 ; 3,4 ; 2,6 ; 3,5$ for

(a) ${ }^{13} \mathrm{C}$ isotopomers

(b) ${ }^{81} \mathrm{Br}$ isotopomers

(c) ${ }^{13} \mathrm{C}_{2}$ isotopomers

(d) ${ }^{81} \mathrm{Br}^{13} \mathrm{C}$ isotopomers

(e) ${ }^{81} \mathrm{Br}^{13} \mathrm{C}_{2}$ isotopomers

The heavy $\left({ }^{13} \mathrm{C}\right.$ and $/$ or $\left.{ }^{81} \mathrm{Br}\right)$ atoms are encircled. The sets for isotopologues comprising ${ }^{81} \mathrm{Br}_{2}$ (i.e., ${ }^{81} \mathrm{Br}_{2}{ }^{13} \mathrm{C}$ and ${ }^{81} \mathrm{Br}_{2}{ }^{13} \mathrm{C}_{2}$ ) are identical to those for ${ }^{13} \mathrm{C}$ and ${ }^{13} \mathrm{C}_{2}$, respectively. 


\section{Table S1}

\begin{tabular}{|l|l|l|}
\hline Standard & Producer & Location \\
\hline Dibromoanilines & Alfa Aesar & Tewksbury, MA \\
\hline 2,$4 ; 2,5$ & Enamine & Monmouth Jct, NJ \\
\hline 2,6 & Oakwood Chemicals & Estill, SC \\
\hline 3,4 & Combi Blocks & Manchester, United Kingdom \\
\hline 3,5 & Accela & San Diego, CA \\
\hline Tribromoanilines & Sigma Aldrich & St. Louis, MO \\
\hline $2,4,5$ & Enamine & Monmouth Jct, NJ \\
\hline $2,4,6$ &
\end{tabular}


Figure S1
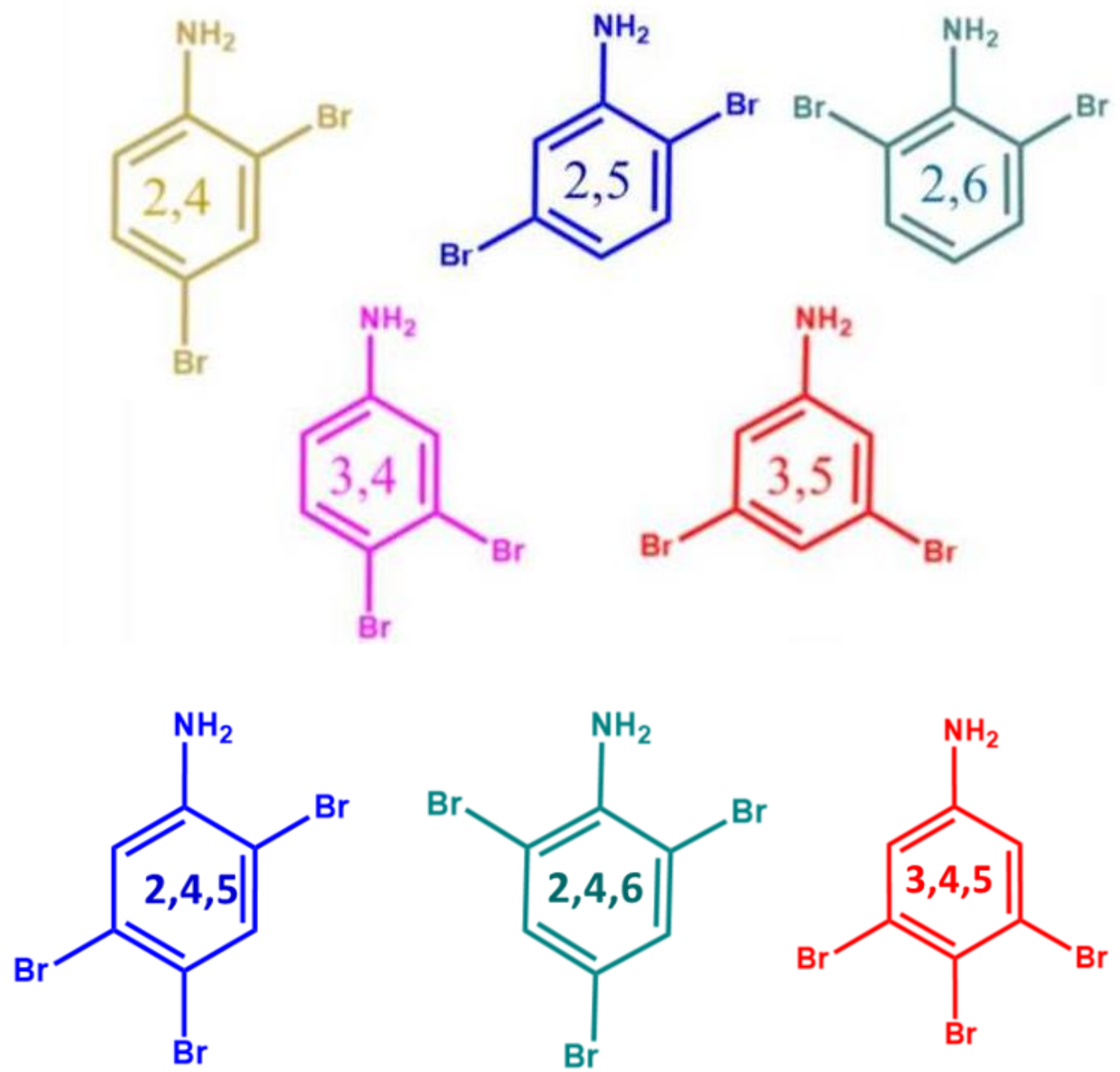
Figure S2a<smiles>Nc1cccc(Br)c1Br</smiles><smiles>Nc1cccc(Br)c1Br</smiles><smiles>Nc1cccc(Br)c1Br</smiles><smiles>Nc1cccc(Br)c1Br</smiles><smiles>Nc1cccc(Br)c1</smiles><smiles>Nc1ccc(Br)cc1Br</smiles><smiles>Nc1ccc(Br)cc1Br</smiles><smiles>Nc1ccc(Br)cc1Br</smiles><smiles>Nc1ccccc1Br</smiles><smiles>Nc1cccc(Br)c1</smiles><smiles>Nc1cc(Br)c(Br)c(N)c1Br</smiles><smiles>Nc1cccc(Br)c1</smiles><smiles>Nc1ccc(Br)c(Br)c1</smiles><smiles>Nc1ccc(Br)c(Br)c1Br</smiles><smiles>Nc1cccc(Br)c1Br</smiles><smiles>Nc1ccc(Br)c(Br)c1</smiles><smiles>Nc1cccc(Br)c1Br</smiles><smiles>Nc1cc(Br)ccc1Br</smiles><smiles>Nc1c(F)cccc1Br</smiles><smiles>Nc1c(F)cccc1Br</smiles><smiles>Nc1ccccc1Br</smiles><smiles>Nc1cc(Br)cc(Br)c1</smiles><smiles>Cc1cc(N)cc(Br)c1</smiles> 
Figure S2b<smiles>[B]c1cc(Br)ccc1N</smiles><smiles></smiles><smiles>Nc1ccc(Br)c(Br)c1</smiles><smiles>Nc1ccc(Br)c(Br)c1</smiles><smiles>Nc1cccc(Br)c1Br</smiles><smiles>Nc1cccc(Br)c1Br</smiles><smiles>Nc1cc(Br)ccc1Br</smiles><smiles>Nc1cc(Br)ccc1Br</smiles><smiles>Nc1cc(Br)cc(Br)c1</smiles><smiles>Nc1c(Br)cccc1Br</smiles> 
Figure S2c<smiles>Nc1cccc(Br)c1OCc1cccc(Br)c1</smiles><smiles>Nc1cccc(Br)c1Br</smiles><smiles>Nc1ccccc1Br</smiles><smiles>Nc1cccc(Br)c1Br</smiles><smiles>Nc1cccc(Br)c1Br</smiles><smiles></smiles><smiles>Nc1ccccc1Br</smiles><smiles>Nc1cccc(Br)c1Br</smiles><smiles>Nc1cccc(Br)c1Br</smiles><smiles>Nc1ccccc1Br</smiles><smiles>Nc1ccccc1Br</smiles><smiles>Nc1cccc(Br)c1Br</smiles><smiles>Nc1cccc(Br)c1Br</smiles><smiles>Nc1ccccc1Br</smiles><smiles>Nc1cccc(Br)c1Br</smiles> 

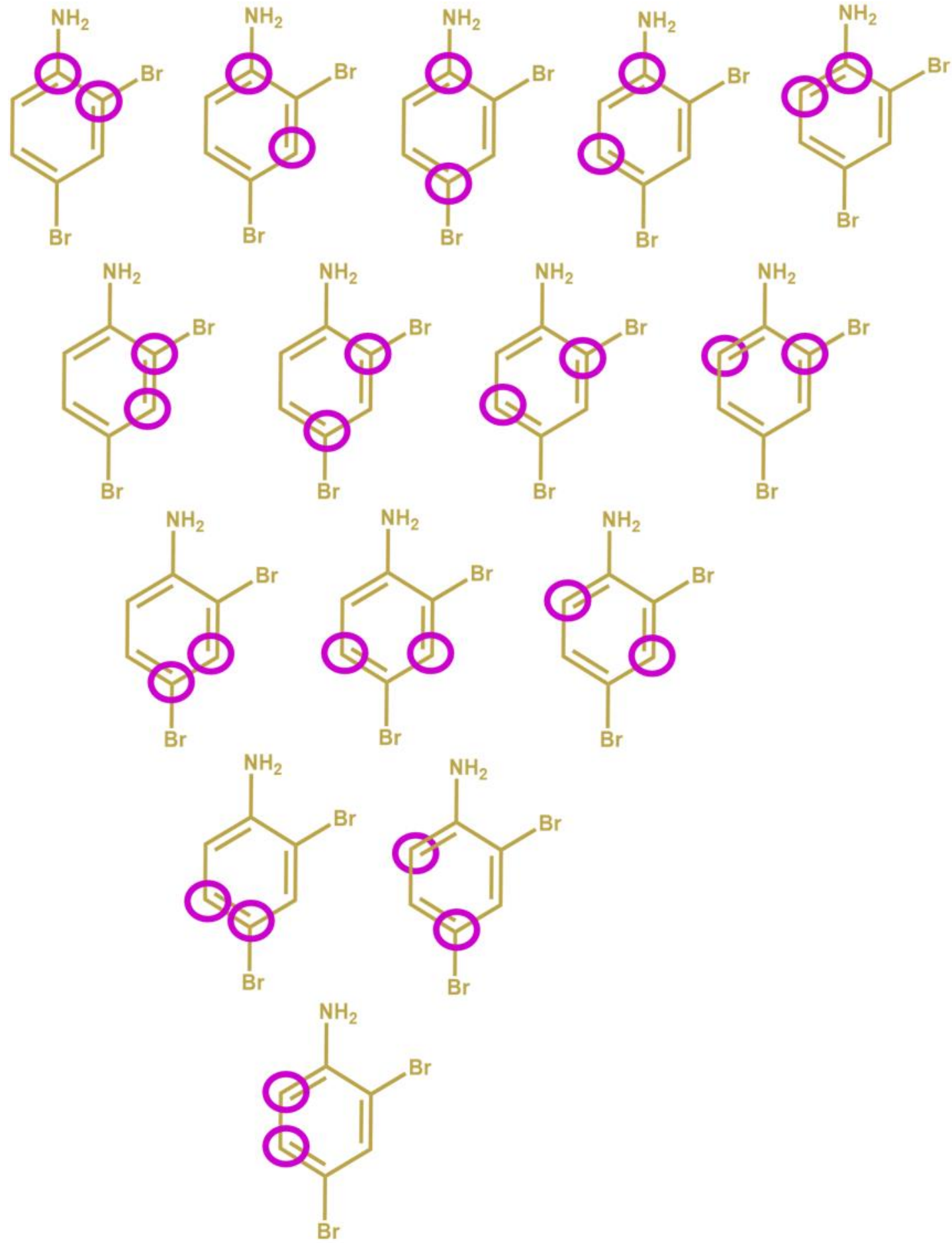
<smiles>NC(=O)COc1ccc(Br)cc1N</smiles><smiles>NC(=O)COc1c(N)ccc(Br)c1Br</smiles><smiles>Nc1cc(Br)c2c(c1)C1C=C(Br)C2CC1</smiles><smiles>Nc1ccc(Br)cc1Br</smiles><smiles>Nc1cc(Br)ccc1C(=O)O</smiles><smiles>Nc1cc(Br)cc2ccccc12</smiles><smiles>Nc1cc(Br)c2c(Br)c1C(Br)=C2Br</smiles><smiles>Nc1cc(Br)ccc1Br</smiles><smiles>Nc1cc(Br)ccc1Br</smiles><smiles>Nc1cc(Br)ccc1Br</smiles><smiles>Nc1cc(Br)ccc1Br</smiles><smiles>Nc1cc(Br)ccc1Br</smiles><smiles>Nc1cc(Br)ccc1Br</smiles> 

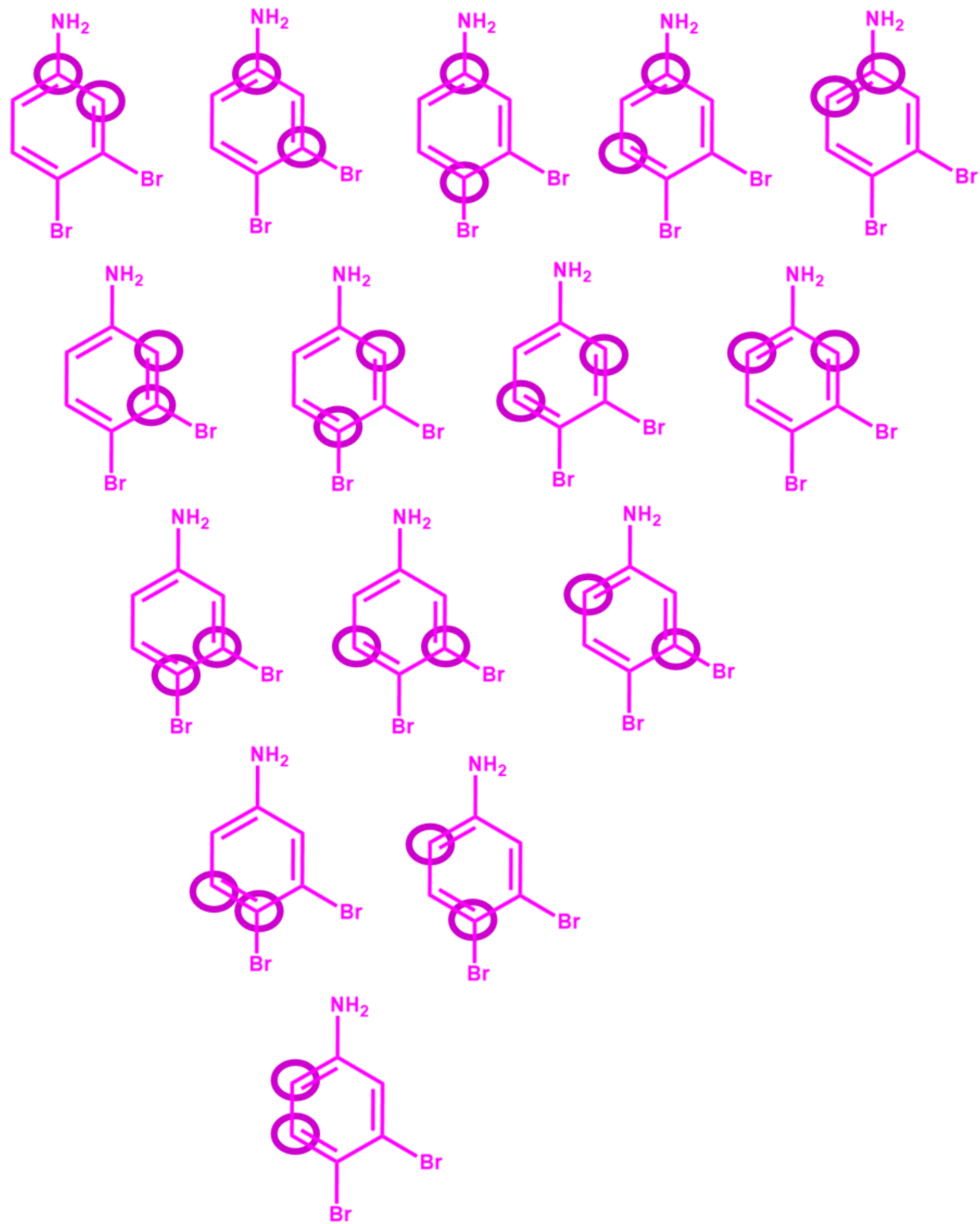


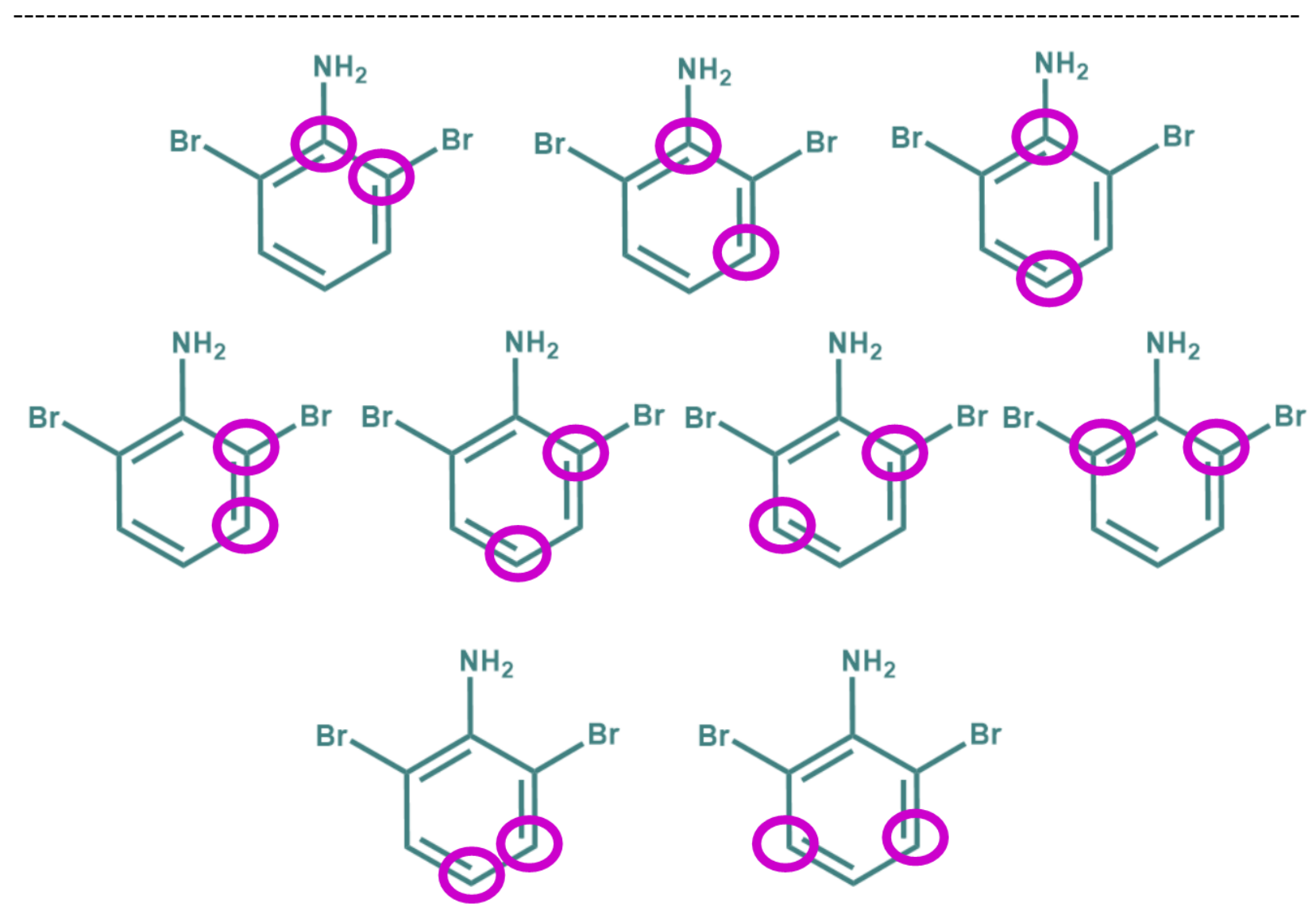



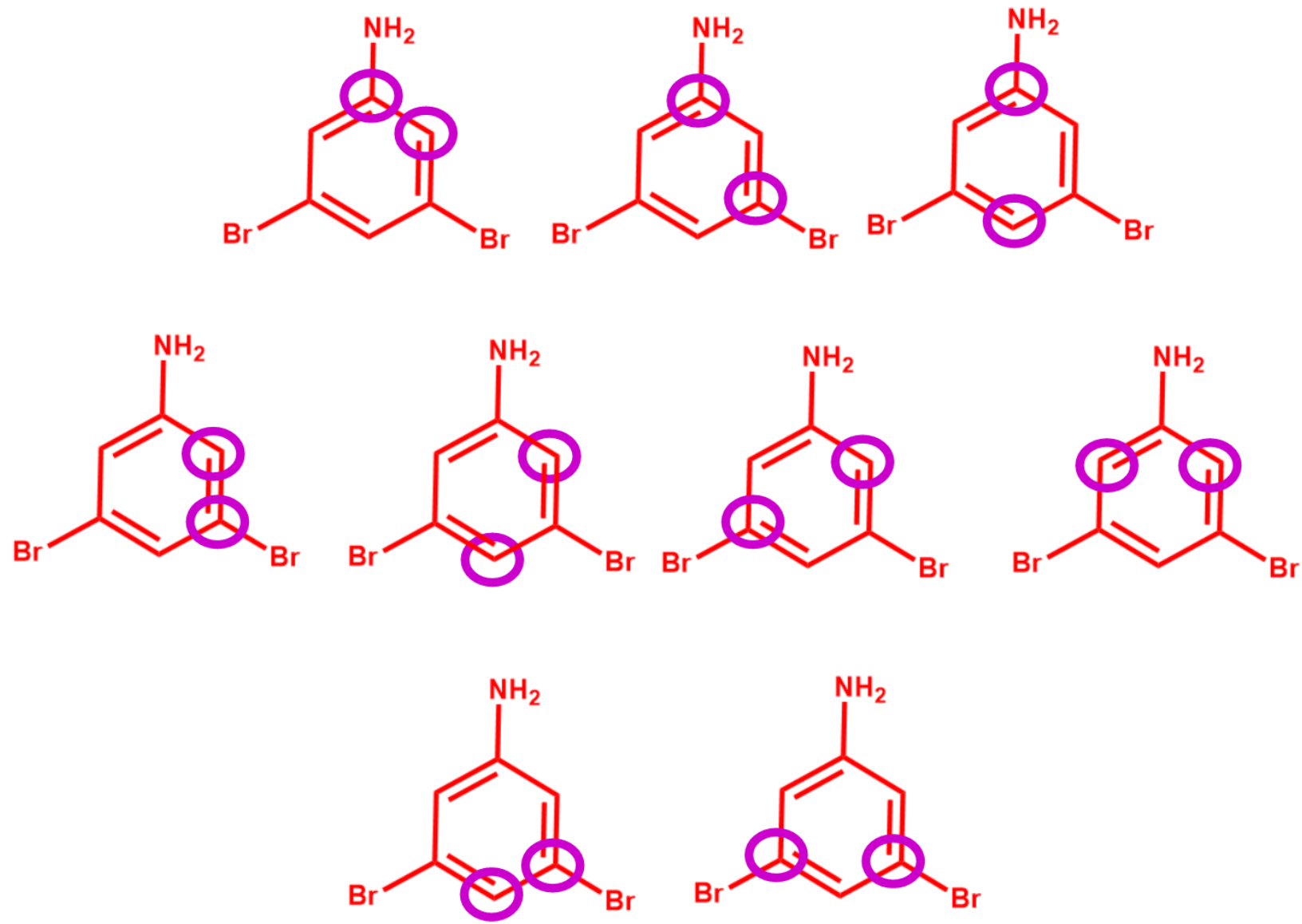
Figure S2d

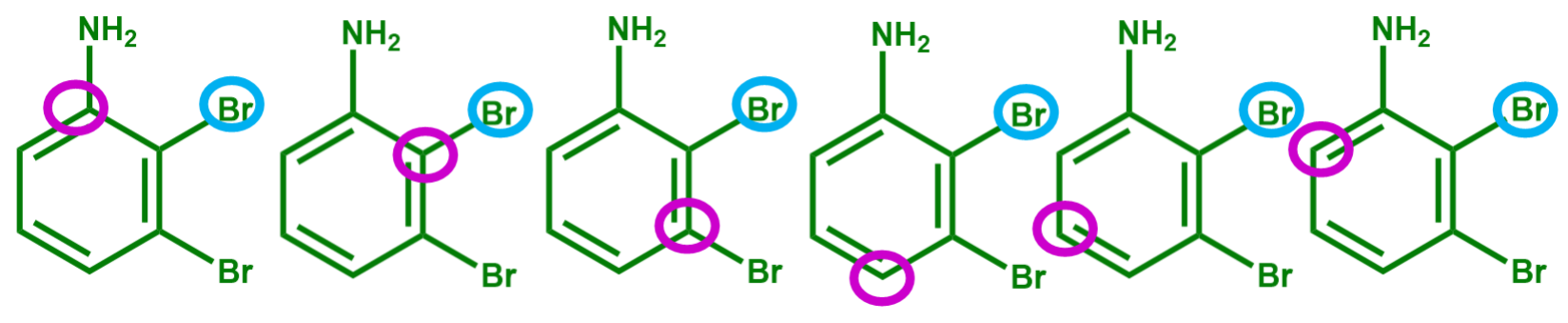<smiles>Nc1cccc(Br)c1Br</smiles><smiles>Nc1cccc(Br)c1Br</smiles><smiles>Nc1cccc(Br)c1Br</smiles><smiles>Nc1cccc([Se])c1Br</smiles><smiles>NOc1cccc(Br)c1</smiles><smiles>Nc1ccc(Br)cc1</smiles><smiles></smiles><smiles>[B]c1cc(Br)cc(-c2cc(Br)cc([O+]c3ccccc3N)c2)c1N</smiles><smiles>NOc1cccc(Br)c1</smiles><smiles>Nc1ccc(Br)cc1Br</smiles><smiles></smiles><smiles>Nc1ccc(Br)cc1Br</smiles><smiles>Nc1ccc(Br)cc1Br</smiles><smiles>Nc1ccc(Br)cc1Br</smiles> 
<smiles>Nc1cc(Br)ccc1[B]c1cc(Br)cc(Br)c1N</smiles><smiles>Nc1cc(Br)c(Br)c(-c2ccc(Br)c(Br)c2)c1</smiles><smiles>Nc1cc(Br)cc(C(=O)Oc2c(N)ccc(Br)c2Br)c1</smiles><smiles>Cc1cccc(N)c1Br</smiles>

(Br)<smiles>Cc1ccc(N)cc1Br</smiles>

(Br)<smiles>Cc1ccc(N)cc1Br</smiles>

(Br)<smiles>Nc1cccc(Br)c1</smiles>

(Br)<smiles>Cc1ccc(N)cc1Br</smiles>

(Br)<smiles>Cc1ccc(N)cc1Br</smiles>

Bi 


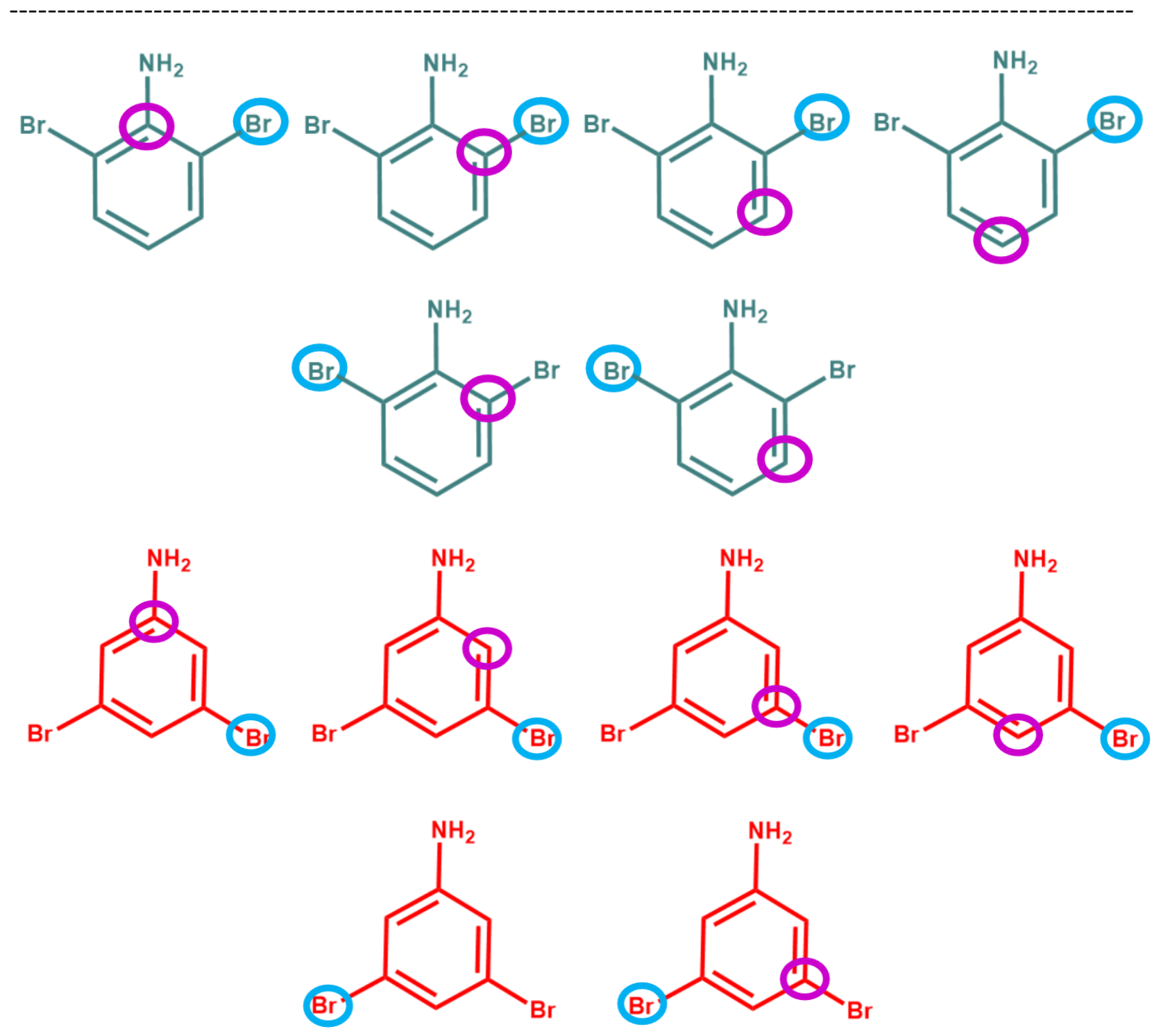




\section{Figure S2e}

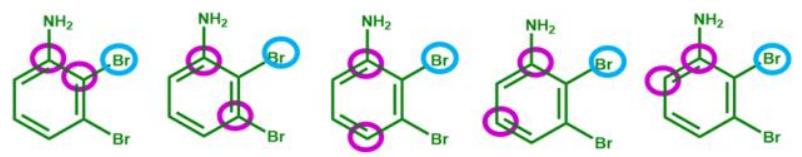
$\mathbb{B}_{\mathrm{Br}}^{\mathrm{N}}$ क्ष

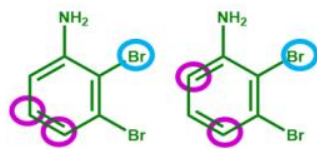

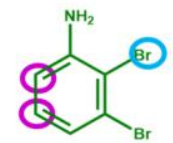

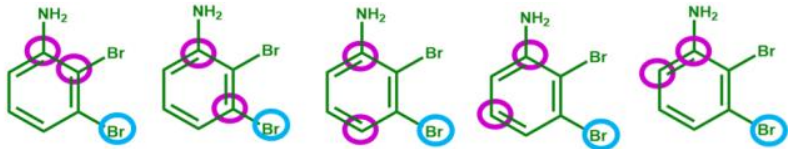

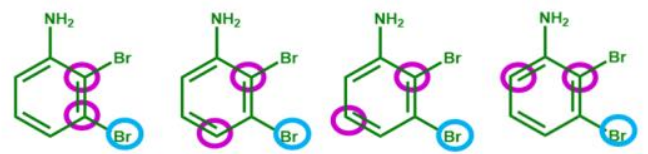

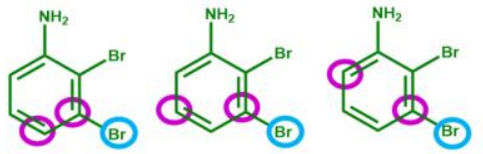

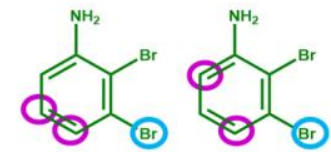<smiles>CCCc1c(O)cccc1O</smiles>

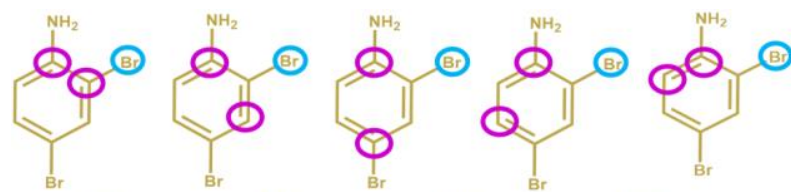

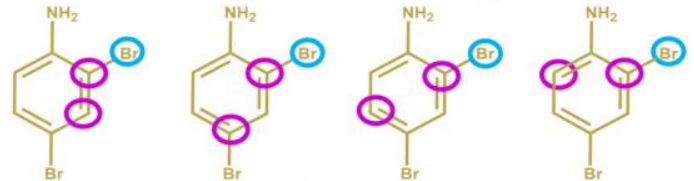<smiles>Cc1ccc(O)c(C)c1O</smiles><smiles>Cc1ccccc1O</smiles><smiles>CC1CCCCC1CO</smiles>

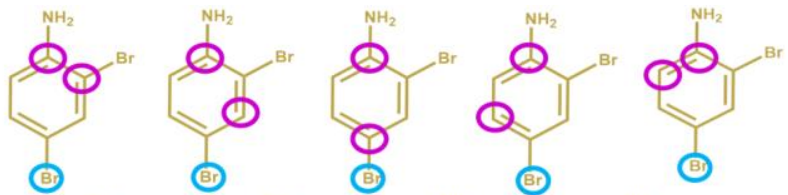

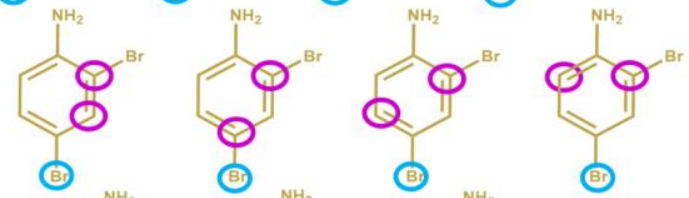

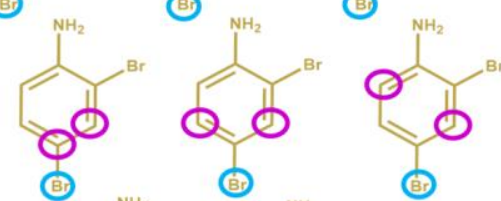

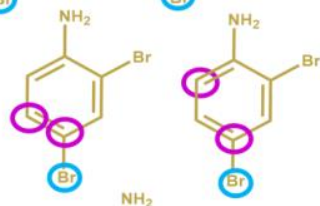

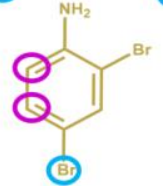


"
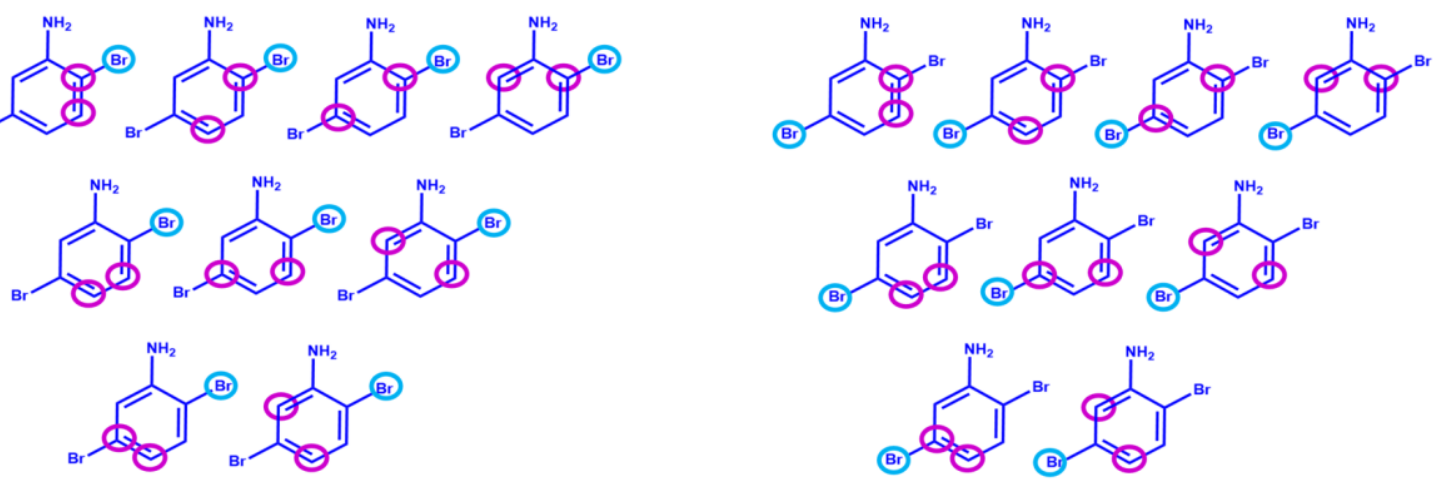

Br
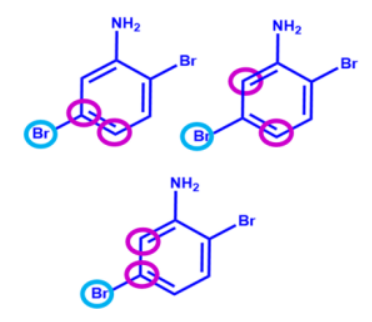

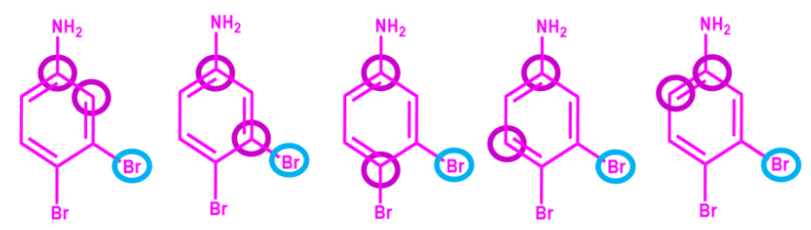

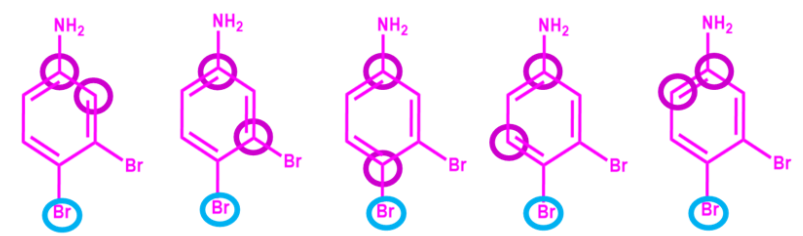

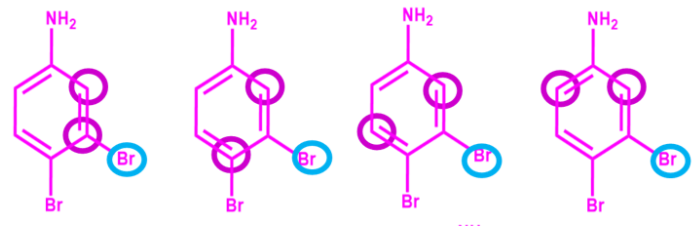<smiles>C1CCOC1</smiles>

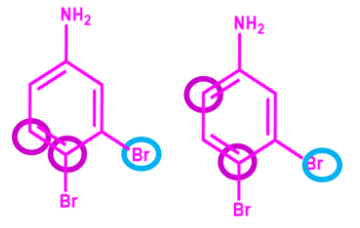

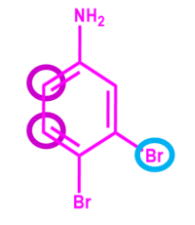

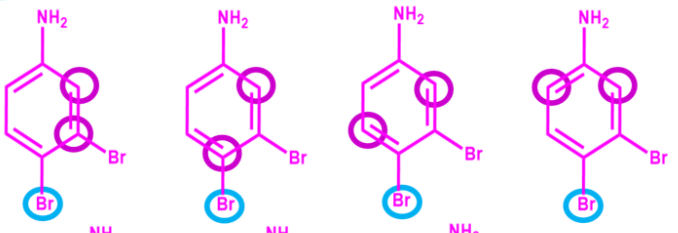<smiles>C1CCOC1</smiles>

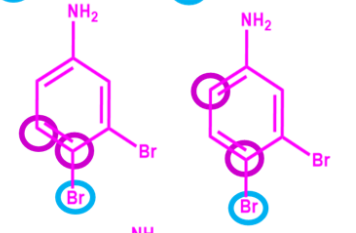<smiles></smiles> 

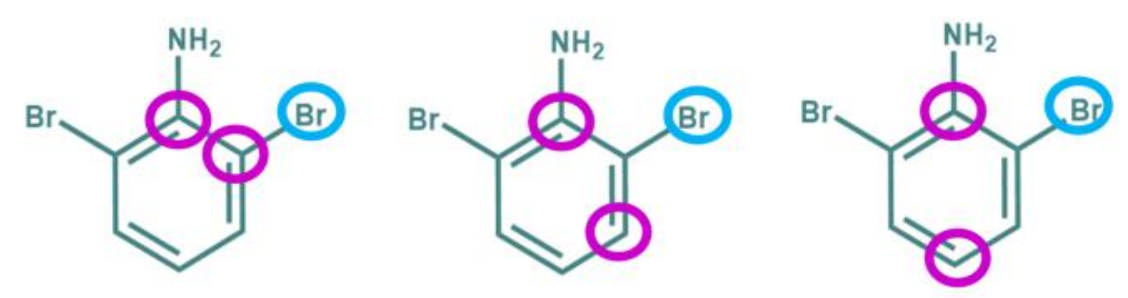

B.<smiles>Nc1ccc(Br)c(Br)c1</smiles><smiles>Nc1c(Br)cccc1Br</smiles><smiles>Nc1c(Br)cccc1Br</smiles><smiles>Nc1cc(Br)ccc1O</smiles><smiles>Nc1c(Br)cccc1Br</smiles><smiles>Nc1c(Br)cccc1OCc1ccccc1</smiles><smiles>Nc1ccccc1-c1cccc(Br)c1</smiles><smiles>Nc1c(Br)cccc1Br</smiles><smiles>Nc1c(Br)[c-]ccc1Br</smiles><smiles>Nc1c(Br)cccc1Oc1ccccc1</smiles> 
<smiles>Nc1ccc(Br)cc1OCc1ccccc1</smiles><smiles>CC(Br)(Oc1cc(N)ccc1Br)c1ccccc1</smiles><smiles>Nc1cc(Br)ccc1Br</smiles>
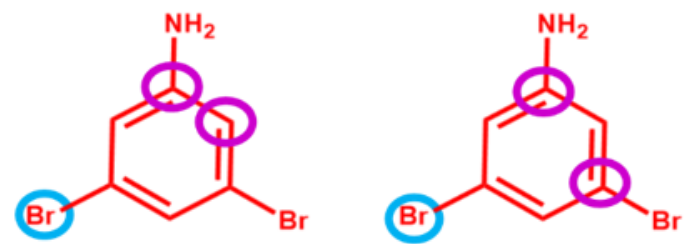<smiles>Nc1cc(Br)cc(Br)c1Br</smiles><smiles>Nc1cc(Br)cc(Br)c1</smiles>
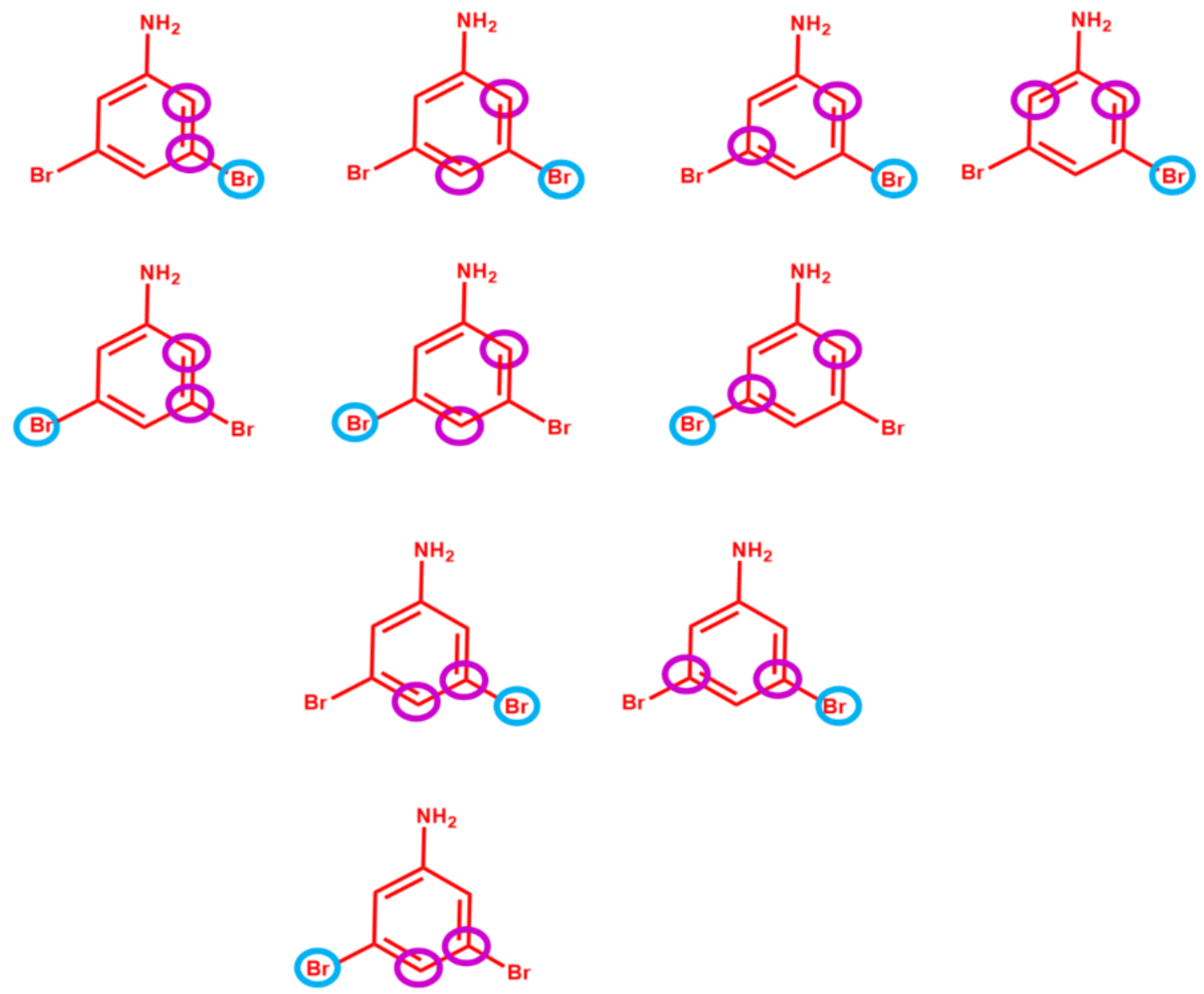